\title{
Chinese and American Refusal Strategy: A Cross-cultural Approach
}

\author{
Yinling Guo \\ Foreign Languages Department, Zhengzhou Institute of Aeronautical Industry Management, Zhengzhou, China \\ Email: guoyinling66@163.com
}

\begin{abstract}
This study investigated both Chinese and American refusal speech act from the perspectives of cross-cultural communication using a modified version of the discourse completion test (DCT) developed by Beebe et al. (1990). 60 US college students and teachers and 60 Chinese college students and teachers are interviewed. The findings indicate that there are more similarities than differences among the Chinese and Americans in making refusals. Both groups preferred to use indirect refusal strategies rather than direct ones and preferred the strategies of reason, statement of alternative and regret. However, the American groups utilized a greater proportion of direct strategies than did the Chinese subjects on average. The differences can be attributed to cultural differences between Chinese and American Culture.
\end{abstract}

Index Terms—refusal, refusal strategy, speech act, cultural difference

\section{INTRODUCTION}

In cross-cultural communication, differences in language use have been noted to be a factor for communication breakdown or pragmatic failure. The differences can be attributed to the ways in which people of a speech community customarily associate forms with meanings. This association could vary across languages and is related to the socio-cultural beliefs and values of the speech community. The culture-specificity of language is particularly evident in speech acts.

The speech act of refusing in a foreign language is a complex task because it requires the acquisition of the socio-cultural values of the foreign language culture. Refusal is culture-specific, so social-cultural factors such as social distance and power between participants are among the most important factors, yet their relative importance can interact with other situational factors and might be subject to cultural variation (Blum-Kulka, S., House, and G. Kasper, 1989). In essence, meaning shifts from culture to culture, therefore, the intended meaning of refusing should be interpreted concerning cultural differences.

There are great cultural differences between Chinese and American Cultures. According to the researches of Hofstede (1984) and Scollon (2000), China is considered to be a country with a collectivistic culture and America an individualistic culture. Cultural differences between China and America may be reflected in various speech acts. How speakers from countries with different cultures refuse in casual conversations and how politeness is constrained by culture aroused the interest of the present study.

Refusals were not as much studied but are being paid increasing attention to: refusals (Beebe, Takahashi, \& Uliss-Weltz, 1990; Bardovi-Hartford, 1990; Liao and Breshnahan, 1996; Blum-Kulka and Olshtain 1984; Gass 1999; Takahashi and Beebe 1987; Nelson and Cason 2002 ). Most Cross-cultural studies of the speech act of refusing have investigated between varieties of English or English and other languages like Japanese, Arabic, Spanish Germany and so forth. Fewer studies on refusals between Chinese and English have appeared in the literature (Wang 2001; Yao Jun 2003; Xu et al, 2003; Chen, H.J., 1996).

Some studies on refusals were conducted both abroad and home. A major study (Beebe et al. 1990) compared the refusal given by native speakers of Japanese and native speakers of English. The findings of Beebe et al. (1990) reveal the interaction of status with the directness of the refusals. Americans usually employed a form of indirect communication in refusing all situations. Japanese, however, tended to use more direct strategies when addressing a lower status person and more indirect strategies when refusing persons of higher status.

Liao and Breshnahan (1996) compared American English and Mandarin Chinese refusal strategies. The findings are: both Taiwanese and Americans utter the politeness markers of apology in the similar frequency. Americans are less likely to refuse a friend, Chinese a family member. They proposed a politeness hypothesis of 'marginally touching the point'.

Wang Aihua (2001) made a contrastive sociopragmatic analysis of different formulaic expressions in refusal and different strategies employed by the Chinese and the Americans in interpersonal communications. Her study focuses on the structural analysis of refusal mode and its discourse realization patterns in terms of words, phrases and sentence patterns in interpersonal communications. Her findings indicate that Brown and Levinson's theory of politeness has its universality. The three social factors (i.e. social status, social distance and ranking of imposition) really affect the weight of an FTA, but affect is also important. In refusing, being indirect is really related to being politeness, but not all 
indirect utterances are polite.

\section{Purpose AND ReseArch Question}

This study attempts to shed light for cross-cultural communication and may help alleviate uneasiness and barriers in interpersonal interactions between people of different culture. The research questions are: Does the frequency of direct and indirect strategy use differ between Chinese and North Americans? Do different initiating acts as well as other social factors like status and social distance of the interlocutors affect Chinese and North Americans' refusal strategies? What implications do these differences have in cross-cultural communication?

\section{Methodology}

This is an empirical study on Chinese and English refusal strategies. Basically, the present study adopts both qualitative and quantitative methods. In describing the speech act of refusing here, we are assuming that there are two participants - one is the speaker, the other is the hearer. The Speaker $(\mathrm{S})$ is referred to as the refuser and the Hearer $(\mathrm{H})$ the refusee.

\section{A. Subjects}

Altogether, 120 subjects participated in this research. They consisted of 60 Chinese college students and teachers from Zhengzhou Aeronautical Industry Management and 30 Americans college students from undergraduate students at Iowa State University and 30 English teachers from America working in China. The 60 Chinese students and teachers are all non-English majors because they are not much influenced by the western culture. Regarding the gender, 78 subjects out of 120 are male and 42 female. Chinese subjects consist of 38 male and 22 female. American subjects consist of 40 male and 20 female. Their ages range from 20 to 65. To a certain extent, the speech act from the campus reflects the speech act of the whole society.

\section{B. The Instrument}

This study is based on analyzing questionnaire made between the American and the Chinese. A modified version of Discourse Completion Test (DCT) employed by Beebe et al. (1990) was used. The present modified version of DCT consists of eight situations. The eight situations have been used and tested in an unpublished Doctor dissertation by Hongyin Julie Chen (1996), two published papers by Wang Aihua in Foreign Language Teaching and Research (2001). Each situation was followed by a space for the subjects to fill in the particular refusal. Intended to be cross-culturally and cross-linguistically common, the situations in the DCT (e.g. borrowing a car, receiving and invitation, etc.) are situations likely to happen to both Chinese and American college students. Social variables like relative power, social distance and ranking of imposition are taken into consideration. The eight situations for study involve obvious status relationship and social distance between the interlocutors (see Table 1).

TABLE 1:

CONTENTS OF THE QUESTIONNAIRE

\begin{tabular}{l|l|l}
\hline Situations & Social Distance & Social Power $^{*}$ \\
\hline S1 Colleague requests to borrow a car & Neutral & Equal \\
\hline S2 Supervisor requests to work overtime & Neutral & Higher \\
\hline S3 Friend invites to dinner & Near & Equal \\
\hline S4 Employee invites to dinner & Neutral & Lower \\
\hline S5 Friend offers to clean up coffee spilt & Near & Equal \\
\hline S6 Friend's mother offers lunch & Neutral & Equal \\
\hline S7 Secretary offers to type & Neutral & Lower \\
\hline S8 Spouse suggests keeping reminders & Nearer & Equal
\end{tabular}

The questionnaire consists of two parts: personal information and eight situations. The situations consist of two requests, two invitations, three offers and one suggestion. The factors of social distance, power gap and ranking of imposition are taken into consideration. The characters involved in the situations of the DCT are friends, colleagues, acquaintances (friend's mother) and intimates (husband and wife). Social distance between intimates like husband and wife is nearer and they share the same power. As for colleagues and acquaintances, their social distance is neutral and they are equal in power. Good friends would be classified as near because of the closeness of their relationship, but they are equal when they are together.

The characters in the questionnaire were mainly described as acquaintances. In order to compare preference patterns by the two groups, the ratio direct to indirect strategies employed by each group with lower, equal, or higher status interlocutor item types was calculated. A t-test was conducted in SPSS 10.0 in order to determine whether observed differences in average frequency of strategies employed by each group were statistically significant.

\section{Data Collection}

To ensure the reliability and validity of the data, we asked 10 Chinese students at Zhengzhou Institute of 
Aeronautical Industry Management to answer the questionnaire so as to see the appropriateness of these situations. We made some small modification. Then, we translated it into English and sent it our Paul, an English teacher from America, make sure that each situation is appropriate and feasible and the language has no mistakes. Finally, we did the questionnaire both in Zhengzhou Institute of Aeronautical Industry Management of China and Kansas State University of America.

\section{Data Analysis}

After the DCT questionnaires had been collected, the responses on the DCT were categorized. In order to arrive at a set of strategies, we first divide the utterances into semantic units; each of which is a smallest, complete unit of semantic information that could stand alone and be understood by it self. The semantic units in a response were then categorized using the widely used classification system developed by Beebe, Takahashi, and Uliss-Weltz (1990) (see Appendix). And the entire response could be characterized by a semantic formula, which is a combination of semantic units. For example, the situation in which one's supervisor asks to work overtime on Saturdays, in refusing, the respondent may give an answer. (see [1]) This response can be divided into three units, each of which falls into a corresponding semantic category in the taxonomy. (as shown in the brackets):

[1] (i) I'm sorry, Sir. (regret)

(ii) But I need a day off. ( reason)

(iii) So I'm afraid I can't work on Saturdays. (direct refusal)

Descriptive statistics were calculated in order to determine measures of central tendency and dispersion for (1) full-test refusal patterns by Chinese and American groups, including total strategies used, strategies per item, total direct strategies, total indirect strategies, and proportion or direct versus indirect; (2) distribution of refusal strategies in response to the initiating act in percentage.

\section{RESULTS AND DISCUSSION}

Results are analyzed according to frequency of strategy use, the distribution of refusal strategies and effect of interlocutor status and social distance between interlocutors.

\section{A. Frequency of Strategies Used}

To answer the first research question: Does the frequency of direct and indirect strategy use differ? The means of total direct strategies and the means of the total indirect strategies for each of the Chinese and American groups are compared.

TABLE 2:

MEANS AND STANDARD DEVIATIONS OF TOTAL DIRECT AND INDIRECT REFUSAL STRATEGY USE BY CHINESE AND AMERICANS

\begin{tabular}{l|l|l|l|l|l}
\hline Subj. & Statistic & Total & Per item & Direct & Indirect \\
\hline \multirow{2}{*}{$\begin{array}{l}\text { Full } \\
(N=120)\end{array}$} & Mean & 17.52 & 2.19 & 2.79 & 14.73 \\
\cline { 2 - 6 } & SD & 3.09 & 0.71 & 0.91 & 6.75 \\
\hline \multirow{2}{*}{$\begin{array}{l}\text { USA } \\
(N=60)\end{array}$} & Mean & 17.72 & 2.22 & 3.25 & 14.47 \\
\cline { 2 - 6 } $\begin{array}{l}\text { China } \\
(N=60)\end{array}$ & SD & 3.45 & 0.71 & 0.95 & 6.31 \\
\cline { 2 - 6 } & Mean & 17.32 & 2.17 & 2.33 & 14.98 \\
\hline
\end{tabular}

On average, the American group utilized slightly more refusal strategies (2.21 strategies per item) than did the Chinese group (2.16 strategies per item). In order to test whether the observed difference was statistically significant, SPSS 10.0 was used. This difference was found to not be statistically significant on the basis of a t-test for mean differences between Chinese and American groups ( $\mathrm{p}=0.48>0.05)$. However, individuals within each of the two groups were variable in the number of strategies they utilized in refusing. Individuals in the American group ranged from an average of 1.25 3.25 strategies per refusal, while individuals in the Chinese group ranged from an average of 1.38 .00 strategies per refusal. On average, both the Chinese and American groups utilized more indirect refusal strategies than direct refusal strategies, as reflected in Table 2. However, the Chinese group was observed to utilize a greater proportion of indirect versus direct strategies than did the American group. The Chinese group utilized 6.42 times as many indirect (96 percent of the total strategies) versus direct refusal strategies, while the American group utilized 4.45 times as many indirect ( 91 percent of the total strategies) versus direct refusal strategies. In addition, we observed that the Chinese subjects used less direct strategies. A typical example of a Chinese refusal that consists of both direct and indirect strategies is illustrated in [2].

[2] 不用了, (direct refusal) // 我家地毯早就该清洗了, (reason) // 不必在意, (let the interlocutor off the hook) // 我时间我自己清理。(statement of alternative)

A typical example of a refusal in the same situation by an American using direct and indirect strategies is illustrated in [3].

[3] No, please. (direct refusal) // I have some special cleaning liquid I will use. (reason) I would prefer to take care of it, (statement of alternative) // thank you. (consideration of interlocutor's feelings) // Please don't worry. (let the interlocutor off the hook) // it will be just fine. (let the interlocutor off the hook) 


\section{B. Distribution of Refusal Strategies in Response to the Initiating Act in Percentage}

\section{Refusal to requests}

Requests are threats in that they impose on the freedom of action the hearer. The hearer has to make a choice, either to accept of refuse. In either case, some sort of challenge to face is involved (Richards, 1982, p.66).

TABLE 3:

DISTRIBUTION OF REFUSAL STRATEGIES IN RESPONSE TO REQUESTS IN \%

\begin{tabular}{|c|c|c|c|c|c|c|c|c|c|c|}
\hline \multirow{2}{*}{ Item } & \multirow{2}{*}{ Country } & \multirow{2}{*}{$\begin{array}{l}\text { Total } \\
\text { Strategies }\end{array}$} & \multirow{2}{*}{$\begin{array}{l}\text { Mean } \\
\text { strategies }\end{array}$} & \multirow{2}{*}{\begin{tabular}{|l} 
Direct \\
strategies
\end{tabular}} & \multicolumn{6}{|c|}{ Indirect strategies } \\
\hline & & & & & Reason & Alternative & Regret & Set Condition & Principle & Others \\
\hline \multirow{2}{*}{1} & China & 136 & 2.27 & 5.00 & 108.0 & 25.00 & 55.0 & 1.67 & & 33.33 \\
\hline & USA & 134 & 2.23 & 56.67 & 66.67 & 33.33 & 46.67 & 1.67 & 3.33 & 15.00 \\
\hline \multirow{2}{*}{2} & China & 108 & 1.80 & 10.00 & 70.00 & 25.00 & 11.67 & 8.33 & 5.00 & 40.00 \\
\hline & USA & 128 & 2.10 & 33.33 & 60.0 & 23.33 & 26.67 & 28.33 & 18.33 & 21.67 \\
\hline
\end{tabular}

Table 3 shows that in declining requests, one contrasting difference is the use of direct strategies between the Chinese and American groups. In the first situation, the total strategies used by the two groups are almost the same and is not statistically significant $(\mathrm{p}=0.80>0.05)$ (refer to Table 8$)$ : Both groups tend to use indirect strategies instead of direct ones. Americans (56.67\%) employed 11 times as many direct strategies as that used by the Chinese (5\%); Many Americans subjects do not hesitate to show their unhappiness. When they feel justified in their behavior, many of them are a little critical about the colleague's dependence on using the car and tend to state their principle. Chinese subjects find it hard to refuse the colleague straightforward. As a result, few employed direct refusal strategy and the majority of the subjects resort to other indirect strategies. But not all the indirect utterances are polite. Example [5] is an example, the speaker doesn't criticize the colleague, but what he said sounded very ironic and impolite.

[4] Sorry, (regret) // I cannot lend you my car again. (direct refusal) // I normally do not lend my car to anyone (statement of principle) // and I feel your company should rent a car for you.(statement of alternative)

[5] 不好意思, (regret) // 哥们儿, 刚好被别人借走了。(reason) // 那家伙真烦, (criticism) // 老来借。(reason)

The second situation involves the refusal of a person of higher status than the requestee. Americans subjects still use much more direct refusal strategy than the Chinese. But compared with the first situation, Americans use less of direct strategy (refer to Table 3). However, the total strategies used show some differences and the difference is statistically significant $(\mathrm{p}=0.01<0.05)$ (refer to Table 8). 60 Chinese produced 108 semantic formulas while 60 Americans produced 128, thus the mean strategies are 1.8 and 2.1 for Chinese and Americans respectively. In refusing a high-status, Chinese subjects employed much more statement of alternative than American subjects. But in terms of the strategy of regret, Chinese (11.67\%) use much less than Americans (26.67\%). For example:

[6] 老师, 我周六参加英语辅导班, (reason) // 平时多干点行不行? (statement of Alternative)

[7] Sorry, (regret) // I'd rather not work on Saturdays, (direct refusal) // but I'm willing to work more hours during the week. (statement of Alternative)

\section{Refusal to Invitations}

Generally speaking, the acceptance of the invitation definitely means the cost of time and energy to the invitee and also the invitee is put into an indebted situation hereafter. So responses to an invitation mainly depend on the relationship between people.

TABLE 4:

DISTRIBUTION OF REFUSAL STRATEGIES IN RESPONSE TO INVITATIONS IN \%

\begin{tabular}{|c|c|c|c|c|c|c|c|c|c|c|}
\hline \multirow{2}{*}{ Item } & \multirow{2}{*}{ Country } & \multirow{2}{*}{$\begin{array}{l}\text { Total } \\
\text { Strategies }\end{array}$} & \multirow{2}{*}{$\begin{array}{l}\text { Mean } \\
\text { strategies }\end{array}$} & \multirow{2}{*}{$\begin{array}{l}\text { Direct } \\
\text { strategies }\end{array}$} & \multicolumn{6}{|c|}{ Indirect strategies } \\
\hline & & & & & Reason & Alternative & Consideration of Feelings & Regret & Avoidance & Others \\
\hline \multirow{2}{*}{3} & China & 135 & 2.25 & 14 & 93.33 & 63.33 & 10.0 & 23.33 & 1.67 & 10.0 \\
\hline & USA & 127 & 2.12 & 17 & 76.67 & 30.0 & 23.33 & 43.33 & & 10.0 \\
\hline \multirow{2}{*}{4} & China & 151 & 2.52 & 16 & 103.0 & 46.67 & 33.33 & 18.33 & .16 .67 & 6.67 \\
\hline & USA & 131 & 2.18 & 17 & 80.0 & 21.67 & 66.67 & 11.67 & & 10.0 \\
\hline
\end{tabular}

Table 4 shows that in declining invitations both Chinese and American subjects favor indirect strategies. Different from declining requests, direct strategies used by the two groups in situations 3 and 4 are almost the same, which is a great increase for the Chinese group compared with that in requests. This shows that it's not so hard for the Chinese to refuse an invitation. Chinese subjects seldom provide a direct 'no' to the person who makes the invitation, regardless of the social status of the individual. Common expressions are like “不用了”, “算了”. The majority of Chinese use these expressions much less but favor statement of alternative (63.33\%). The fact that Chinese people don't like to use the expression of regret when declining an invitation doesn't mean that they are not polite, simply because the Chinese “对 不起” is not as applicable to different contexts as its English equivalents such as "I'm sorry" and "excuse me".

Situation Four involves refusing a person with a lower status. The total strategy used by Chinese is 151 and mean strategy 2.52. Americans produced 131 and mean strategy 2.18, which is a little less than the Chinese. The difference in the number of strategy used by the two groups is statistically significant $(\mathrm{p}=0.01<0.05)$ (refer to Table 8$)$. When refusing a lower status employee, Americans used more thanks and positive opinions (66.66\%) but less regret than declining good friends who are supposed to share the same social status. For example: 
[8] Thank you for the invitation, (consideration of interlocutor's feelings) // but I have plans. (reason)

[9] 应该是我登门拜访你们, (statement of alternative) // 但近来较忙, (reason) // 改天大家一起坐坐。(statement of alternative)

One strategy that some Americans employed but didn't exist in the Chinese questionnaires is the statement of principle. It sounds so blunt and should be hard refusals in Chinese. For example:

[10] Thank you, (consideration of interlocutor's feelings) // but I must decline your dinner invitation. (direct refusal) // This is my policy to avoid any possible perception of staff favoritism. (statement of principle)

It is obvious that Americans give explicit reasons no matter refusing a person of equal status or higher-status. Chinese, however, tend to give specific reasons when refusing a high-status but implicitly when refusing a person of lower status.

\section{Refusal to Offers}

The quality of offers is very similar to that of invitations. Both speech acts entail the cost and benefit of the speaker and the hearer.

TABLE 5:

DISTRIBUTION OF REFUSAL STRATEGIES IN RESPONSE TO OFFERS IN \%

\begin{tabular}{|c|c|c|c|c|c|c|c|c|c|c|}
\hline \multirow{2}{*}{ Item } & \multirow{2}{*}{ Country } & \multirow{2}{*}{$\begin{array}{l}\text { Total } \\
\text { Strategies }\end{array}$} & \multirow{2}{*}{$\begin{array}{l}\text { Mean } \\
\text { strategies }\end{array}$} & \multirow{2}{*}{$\begin{array}{l}\text { Direct } \\
\text { strategies }\end{array}$} & \multicolumn{6}{|c|}{ Indirect strategies } \\
\hline & & & & & Reason & Alternative & Consideration of Feelings & Avoidance & Off Hook & Others \\
\hline \multirow{2}{*}{5} & China & 149 & 2.48 & 41.67 & 50.0 & 66.67 & 13.33 & 21.67 & 53.33 & 1. 67 \\
\hline & USA & 167 & 2.78 & 36.67 & 55.0 & 66.67 & & 3.33 & 100 & 16.67 \\
\hline \multirow{2}{*}{6} & China & 130 & 2.17 & 33.33 & 120.0 & 8.33 & 41.67 & & & 13.33 \\
\hline & USA & 137 & 2.28 & 45.0 & 88.33 & 3.33 & 83.33 & & & 8.33 \\
\hline \multirow{2}{*}{7} & China & 128 & 2.13 & 43.33 & 60.0 & 66.67 & 36.67 & & 1.67 & 5.0 \\
\hline & USA & 137 & 2.28 & 36.67 & 43.33 & 48.33 & 70.0 & 3.33 & 18.33 & 8.33 \\
\hline
\end{tabular}

Table 5 shows that Chinese and American subjects use exactly the same amount of direct strategies when putting the direct strategies in situations 5, 6 and 7 together.

Significant differences were found in the use of indirect strategies. In situation 5, Chinese used reason, alternative and avoidance (including topic switch and joke) more than Americans. However, the latter used consideration of the interlocutor's feelings and let the interlocutor off the hook more frequently. The indirect strategies frequently used by the two groups are let the interlocutor off the hook, followed by statement of alternative, reason and avoidance (including topic switch and joke).

[11] 没事, (let the interlocutor off the hook) // 我正准备把地毯送干洗店。(reason) //继续喝, 别破坏了咱们的 兴致。(reason)

[12] No, that's okay, old carpet anyway. Here, get another cup of coffee. I'll clean it up. No problem.

It is also interesting that 13 Chinese (21.67\%) but only one American use joke to minimize an FTA of refusing.

[13] 没事儿，让地毯也喝点儿。

[14] I'll send you the bill, ha ha.

In situation 6, Chinese group used more reason while the American group expressed more thanks. The content of the reasons provided by the two groups are of great difference. 34 (56.67\%) Americans gave the reasons that they were "not hungry", while only one Chinese say so. "I'm not hungry". This reminds us of the directness of the American people.

[15] 不用啦, (direct refusal ) // 我走啦, (statement of alternative) //家里已经做好了。(reason)

It seems that more than half Chinese subjects seldom uttered “谢谢” “您太客气了”, especially among close friends. Americans express their thanks or gratitude whenever it is necessary no matter to the close friends or intimates. But Chinese utters thanks mostly to people who are not so familiar with or a person of higher status.

Situation 7 involves refusing a person of a lower status. The strategies used by both groups are much similar. Americans and Chinese subjects both avoided using a terse "no" hoping to maintain good relationships with employees. Indirect strategies take priority over the direct ones in order to protect the secretary's face and dignity. Chinese group yielded more alternatives (66.67\%) and reasons (60\%) than Americans did, while the American group employed more consideration of the interlocutor's feelings (70\%) and let the interlocutor off the hook (18.33) than the Chinese did. It seems in America and Canada, the relationships between status un-equals are not as hierarchical as in China. The four examples above can show this clearly. American subjects show more concern for the secretary's thoughtfulness. The frequently used strategy - reason falls behind the statement of alternative. This is the only exception in the eight Situations. When refusing an employee for the offer, the person of higher status employed fewer reasons. It might because of the power gap and the familiarity between them. Typing is should be one of a secretary's responsibilities. So offering to do the typing is very natural but refusing is unnatural. So a sound reason is still necessary. Although most of the subjects presented a reason, the majorities did not state the real reason that the report was important. Otherwise, it will make the secretary feel distrusted and inferior. For example:

[16] 还是我自己来吧, (statement of alternative) // 有别的任务够你忙的。(consideration of interlocutor's feelings)

[17] No, (direct refusal) / /thank you. (consideration of interlocutor's feelings) // I might want to change it as I type it. (reason) 


\section{Refusal to a suggestion.}

TABLE 6:

DISTRIBUTION OF REFUSAL STRATEGIES IN RESPONSE TO SUGGESTIONS IN \%

\begin{tabular}{|c|c|c|c|c|c|c|c|c|c|c|}
\hline \multirow{2}{*}{ Item } & \multirow{2}{*}{ Country } & \multirow{2}{*}{$\begin{array}{l}\text { Total } \\
\text { Strategies }\end{array}$} & \multirow{2}{*}{$\begin{array}{l}\text { Mean } \\
\text { strategies }\end{array}$} & \multirow{2}{*}{$\begin{array}{l}\text { Direct } \\
\text { strategies }\end{array}$} & \multicolumn{6}{|c|}{ Indirect strategies } \\
\hline & & & & & Reason & Alternative & Avoidance & Criticism & Acceptance as Refusal & Others \\
\hline & China & 106 & 1.77 & 60.0 & 33.33 & 25.0 & 20.0 & 13.33 & 15.0 & 20.0 \\
\hline & USA & 102 & 1.70 & 60 & 43.33 & 15.0 & 20.0 & 5.0 & 16.67 & 10.0 \\
\hline
\end{tabular}

In Situation 8, the total semantic formulas by the both groups are less than all the previous 7 situations. The Chinese group produced 106, with mean strategies being1.77. The Americans yielded 102 semantic formulas, with mean strategies being 1.7. It's obvious that most subjects use only one semantic formula to refuse her partner. Beebe et al. (1990) claimed that natural examples of American refusals overheard between intimates are shorter than those to acquaintances. Her findings are testified in our data.

One distinct feature of the strategies used in this situation is that direct strategies take priority over the response of noncompliance for both groups. Both Chinese (50\%) and Americans (60\%) refused the suggestion explicitly. Most subjects think there is no need to be polite to the spouse. So only six (10\%) subjects in each group utilized the strategy of consideration of the interlocutor's feeling. Reason ranked second and alternative third for Chinese (see [19]). For Americans, reason was also the second choice but they use a little more than Chinese. Avoidance ranked fourth for Chinese (20\%) and Americans third (20\%). Chinese liked to use jokes to avoid direct refusal, while Americans preferred hedging to avoid disagreement and a fruitless debate. Acceptance that functions as refusals is another strategy used in comparatively high frequency. The desire to agree or appear to agree with $\mathrm{H}$ leads also to pretending to agree, 'Token' agreement, such as, 'Yes, but...' allow S to go in twisting utterances so as to appear to agree to hide disagreement. In effect, rather than a 'No', the S may soften the disagreement. For example:

[18] I've tried that before and it doesn't work.

[19] 我不想这么做, (direct refusal) // 亲爱的。我知道你爱我, (consideration of interlocutor's feelings) // 你当 我的记事本好了。(Joke)

There are $8(13.33 \%)$ Chinese and $3(5 \%)$ Americans returned criticism to the spouse's kindness, because they didn't like people to tell them what to do, especially the loved ones. For example:

[20] 你是不是以为我是老太太啊, 我知道该怎么做。

[21] I don't tell you how to organize yourself... don't tell me.

This kind of strategy seldom appears in the previous situations. Direct strategies were more frequently used among intimate relationships. From the number of criticism used by the Chinese subjects, it seems that Chinese husband and wife respect each other less than their American counterparts. Most Chinese couples seems more direct and rude to each other. As a matter of fact, a careful examination of the data reveals that instead of a linear correlation, the variable of social distance correlates to refusal strategy choice in a different pattern, which is referred to by Wolfson (1989) as "Bulge Theory". This finding proves applicative in this study. We can come to a conclusion that directness tends to rise with increase in familiarity, as well as with the transition from the public to the private.

\section{FINDINGS AND DisCUSSION}

Findings from this study indicate many more similarities than differences among the Chinese and North Americans subjects in making refusals. Both groups prefer to use indirect refusal strategies rather than direct ones. Generally speaking, Americans utilize more direct strategies than Chinese do, but not in all situations. When refusing requests, Americans utilize much more direct strategies. However, when declining invitations and offers Chinese use slightly more direct refusal strategies than Americans did in order to minimize the cost of the interlocutor. Both groups show more similarities when refusing the spouse's suggestions.

We also noted that both groups used reason more than any other strategies. On average, Chinese used more reason and Statement of alternative while Americans employed more regret and consideration of interlocutor's feelings. Although both groups favored reason, the range of content of American speakers' reasons was broader and often more direct and sound unacceptable, which agrees with Bardovi-Hartford's (1991) conclusion. (see [13] \& [14] ). Chinese subjects were more concerned about being indirect, preserving face, and avoiding embarrassment. Most of the respondents softened their refusal with, for example, statements of regret, or consideration of the interlocutor's feelings. Such softeners are expected in face-threatening acts to 'save' the face if the person who requests or invitations (Beebe at al. 1990).

The result proves that different contexts, relative social distance and power in both Western and Chinese societies affect the choice of refusal strategies. Both groups found it hard to refuse friends, colleagues and acquaintances but not intimates. When the social distance is near, people tend to speak directly, otherwise they will express their ideas and opinions in a round about way. Chinese people found it hard to refuse a person with a higher status and tend to be economical in strategy use. When refusing a person of equal or lower status, Chinese usually would employ comparatively more strategies. Americans, however, did not show great contrast as the Chinese. We also got the impression that Americans are very sensitive to their personal rights. It is found from the second situation, 30 of them 
(50\%) mentioned compensate of money and time for being asked to work overtime on Saturdays by the supervisor.

Chinese people are sensitive to the relative age and status. This is not only reflected from the use of strategies but also from the use of address terms. In Liao (1994a), it is indicated that when Chinese people are speaking to a person of high status, they may use the address form again and again to replace the second person pronoun 'you'. In this study, in Situation 2, there is only one (1.67\%) American subject used the address form "Sir", by contrast, 14 (23.33\%) Chinese utter the address form of “老总” or “老板”, before they utter the reason or apologize. In Situation 7, the friend's mother was referred to as “阿姨” by the Chinese group. Chinese group. One third of them used it to show respect to the mother. There is one person in the American group called the mother as "Mrs X".

Language is the carrier of culture and culture reflects itself from language. These similarities and differences in refusal strategies are the manifestation of cultural differences between Chinese and Western Culture. The information from the DCT provides a "window on human interaction" (Gass and Houck, 1999, p.1) and may reflect tendencies in Chinese and North American social norms.

\section{CONCLUSIONS, LIMITATION AND RECOMMENDATION}

These findings highlight the complexities of social interactions, politeness, and face. The similarities of the use of refusal strategies show that people from different cultures share similar views concerning politeness. The differences reveal various politeness stresses. In cross-cultural communication, confusion may arise when different styles of refusal are used as a result of different politeness emphases. To assign a positive value to one strategy or one group and a negative value to the other strategy or group is potentially an obstruction to successful intercultural communication. Americans tend to speak directly. It is the influence of western culture. Being indirect or "beating around the bush" is Chinese culture-specific and language-specific, we can't say will is right or wrong but would understand when we are familiar with each other's language and Culture.

This study investigates Chinese and North Americans' refusal strategies by asking interviewees to respond orally to hypothetical situations. There are some limitations in this study that will be significant to the future study. First, All the participants in this study are from the Universities or colleges. The way they make refusals may be different from the career people or farmers. Therefore, we cannot assume that the findings can be generalized and be applied to all walks of people. Secondly, Although this methodology produced the necessary comparable data, what people believe they would say in a given situation may be different from what they would say if the situation arose in daily interaction. For example, in China, it is rare that a successful performance of inviting is realized in a single utterance. It more often than not takes several talk exchanges. This kind of ritual refusals that occur so frequently in Chinese invitations cannot be observed. The written form also limited the amount of data collected due to time or unwillingness to fill in the questionnaire in about 25 minutes. Thirdly, only eight situations are analyzed and many have been left untouched. Among the eight situations, only one high-status person is refused. So whether the findings here can be applied to other situations remain indefinite and must be confirmed or corrected by future research.

Recommendations for Further Studies

The study leaves much space for follow-up research. Further research is needed to find out how generalizable the findings are and investigate other refusal strategies. In order to do so, choosing one kind of speech act and involving more different status and social variables may achieve satisfactory results. A study on natural speech will be more convincing, because a quantitative study of spoken refusals in completely natural situations will approach to the truth. Third, analysis of ritual refusal in invitations and offers will attract more attention because ritual refusal is Chinese-culture specific.

\section{APPENDIX A: QUESTIONNAIRE IN ENGLISH}

\section{A Survey of Ways of Refusing}

Dear Sir or Madam:

This questionnaire is for an MA thesis. It is for a survey of ways of English refusing. It would be appreciated if you would read each situation carefully and fill in the blanks with what in your opinion would be most appropriate refusal responses. Your answers are not judged as to be true or false, right or wrong. You are expected to write out the statements that reflect your real ideas or opinions. Thanks!

Your age __ Gender_ Nationality

Your first language ___ Level of education completed___ Major

1. At noon, a colleague who is careless comes to borrow your car for his company. He has borrowed your car twice before. You don't want him to borrow it again. What would you say?

2. Your supervisor asks you to work overtime in the Lab on Saturdays from now on, but Saturday is your day off. What would you say?

3. A good friend invites you to dinner on the weekend, but you can't stand his/her wife/husband. What would you say?

4. You are the manager of a company. As the New Year draws near, a new employee, younger than you, invites you 
to dinner at his home. What would you say?

5. Your good friend is at your house for coffee. He accidentally spills a whole cup of coffee on your carpet and makes a mess of it. He insists on cleaning it up for you, but you don't want him/her to. What would you say?

6. You're watching TV at your friend's home. Your friend's mother offers you lunch. What would you say?

7. You are typing an important report. Your secretary offers to do the typing for you. What would you say?

8. Knowing that you tend to be forgetful, your husband/wife kindly suggests "Maybe you can write yourself little notes to remind you." But that's just not your way of doing things. What would you say?

\section{APPENDix B: QUESTIONNAIRE IN CHINESE}

\section{“拒绝”言语行为的问卷调查}

\section{同志们:}

你们好！在日常交往中, 我们每个人都有不得不拒绝别人请求或邀请的时候。此问卷是为研究中国人“拒绝” 言语行为而设计的。请您认真阅读每一个情景, 然后在空白处填上您认为最合适的拒绝的话语（长短不限）。 由于每个人的情况不同，对下列问题的回答也不尽相同，您的答案不存在正确或错误之分，请您尽可能地反映 出自己的真实想法和做法！谢谢您的合作！
您的年龄:
性别:
学历:
专业:

1. 一天中午，一位粗心大意的同事过来说借你的车，又是公事，他这是第三次借你的车了，害怕他以后再借。 你说:

2. 你的老板希望你从现在开始每周六到实验室加班，但是周六是你的休息时间。

你说:

3. 一位好朋友邀请你到他 / 她家吃晚饭，但是你受不了他 / 她的妻子 / 丈夫。

你说:

4. 你是公司的经理, 新年就要到了，一天一位比你年轻的新员工邀请你到他家吃饭。

你说:

5. 你和一位好朋友在你家喝咖啡，他 / 她不小心把一杯咖啡全酒在了地毛上，搞得很脏，所以他 / 她坚持要 打扫一下。

你说:

6. 你在朋友家看电视，朋友的妈妈让你在他家吃晚饭。

你说:

7. 你正坐在电脑前打一份非常重要报告，你的秘书说帮你打。

你说:

8. 你的丈夫 / 妻子知道你爱忘事, 善意地给你建议说“也许你可以做个记录，以便提醒自己。”但你不喜欢这种 方法。

你说:

\section{APPENDiX C: The TAXONOMY OF BEEBE AT AL.}

\section{Direct}

A. Performative (e.g., "I refuse")

B. Nonperformative statement

1."No"

2. Negative willingness/ability (“I can't”. "I won't". "I don’t think so")

\section{Indirect}

A. Statement of regret (e.g., "I'm sorry..."; "I feel terrible...")

B. Wish (e.g., "I wish I could help you...")

C. Excuse, reason, explanation (e.g., "My children will be home that night."; "I have a headache.")

D. Statement of alternative

1. I can do X instead of Y (e.g., "I'd rather..." "I'd prefer...")

2. Why don't do X instead of Y (e.g., "Why don't you ask someone else?" )

E. Set condition for future or past acceptance (e.g., "If you had asked me earlier, I would have ...")

F. Promise of future acceptance (e.g., "I'll do it next time"; "I promise I'll ..."; or "Next time I'll ...")

G. Statement of principle (e.g., "I never do business with friends.")

H. Statement of philosophy (e.g., "One can't be too careful.")

I. Attempt to dissuade interlocutor

1. Threat or statement of negative consequences to the requester (e.g., "I won't be any fun tonight" to refuse an invitation) 
2. Guilt trip (e.g., waitress to customers who want to sit a while: "I can't make a living off people who just order coffee." )

3. Criticize the request/requester, etc. (statement of negative feeling or opinion); insult/attack (e.g., "Who do you think you are?"; "That's a terrible idea!')

4. Request for help, empathy, and assistance by dropping of holding the request.

5. Let interlocutor off the hook (e.g., "Don't worry about." "That's okay." "You don't have to.")

6. Self-defense (e.g., "I'm trying my best." "I'm doing all I can do.")

J. Acceptance that functions as a refusal

1. Unspecific or indefinite reply

2. Lack of enthusiasm

K. Avoidance

1. Nonverbal

a. Silence

b. Hesitation

c. Do nothing

d. Physical departure

2. Verbal

a. Topic switch

b. Joke

c. Repetition of part of request, etc. (e.g., "Monday?")

d. Postponement (e.g., "I'll think about it.")

e. Hedging (e.g., "Gee, I don't know." "I'm not sure.")

III. Adjuncts to Refusals

1. Statement of positive opinion/feeling or agreement (e.g., "That's a good idea..."; "I'd love to...")

2. Statement of empathy (e.g., "I realize you are in a difficult situation.")

3. Pause fillers (e.g., "uhh"; "well"; "oh"; "uhm")

4. Gratitude/appreciation

\section{REFERENCES}

[1] Bardovi-Harlig, Kathleen \& Beverly, Hartford. (1990). Learning to Say 'no': Native and Non-native Rejections in English. Paper Presented at the Conference on Pragmatics and Language Learning, Urbana-Champaign.

[2] Beebe, L. T., Takahashi, \& R. Uliss-Weltz. (1990). Pragmatic transfer in ESL refusals. In R. Scarcella, E. Anderson \& S. D. Krashen eds. On the Development of Communicative Competence in a Second Language. Cambridge, MA: Newbury House.

[3] Birchler G, Robert W., \& John V. (1975). Multi-method analysis of social reinforcement exchange between martially distressed and non-distressed spouse and stranger dyads. Journal of Personality and Social Psychology, 31, 349-306.

[4] Blum-Kulka, S., J. House, \& G. Kasper. (1989). Investigating Cross-Cultural Pragmatics: An Introductory Overview. In S. Blum-Kulka, J. House, and G. Kasper (eds.): Cross-Cultural Pragmatics: Requests and Apologies. Norwood, NJ: Ablex: 1-13.

[5] Chen, Hongyin Julie (1996). Cross-Cultural Comparison of English and Chinese Metapragmatics in Refusal. Unpublished Doctor Dissertation.

[6] Hofstede, G.. (1984). The Cultural Relativity of the Quality of Life Concept. Academy of Management review, 9/3, $389-398$.

[7] Liao, Chao-chih \& Mary I. Bresnahan. (1996). A Contrastive Study on American English and Mandarin Refusal Strategies. Language Science, 18, 703-727.

[8] Nelson, Gayle, et al. (2002). Cross-Cultural Pragmatics: Strategy use in Egyptian Arabic and American English Refusal. Applied Linguistics, 23.2, 163-189.

[9] Olshtain, E., \& Cohen, A.D. (1983). Apology: A Speech-Act Set. In N. Wolfson and E. Judd (eds.), Sociolinguistics and Language Acquisition. Rowley, MA: Newbury House.

[10] Richards, Jacks C. (1982). Talking across Cultures. Language Learning and Communication, 1.1, 61-72.

[11] Scollon, R. \& S. W. Scollon. (2000). Intercultural Communication: A Discourse Approach. Beijing: Foreign Language Teaching and Research Press.

[12] Susan, M. Gass \& Noel, Houck. (1999). Interlanguage Refusals: A Cross-cultural Study of Japanese-English. Berlin: Mouton de Gruyter.

[13] Wolfson, N. (1988). The Bulge: A Theory of Speech Behavior and Social Distance. Second Language Discourse: A Textbook of Current Research. (Ed.). J. Fine. Norwood, NJ: Ablex, 21-38.

[14] Wolfson, N., Marmor, T., \& Jones, S. (1989). Problems in the comparison of Speech Acts across Cultures. In S. Blum-Kulka, J. House, and G. Kasper (Eds.), Cross-Cultural Pragmatics: Requests and Apologies. Norwood. NJ: Ables, 174-196.

[15] Wang, Aihua. (2001).Refusal realization patterns in English and Chinese. Foreign Language Teaching and Research, 3 , 174-240.

[16] Yao, Jun. (2003). Reflections on the difference between western culture and Chinese Culture: a contrastive pragmatic study on refusal strategies. Shandong Foreign Language Teaching Journal, 1, 12-17.

Yinling Guo was born in Zhengzhou City, Henan Province, China in 1966. She received her M.A. degree in English language and 
literature from Foreign Languages Department of Zhengzhou University, China in 2005. Now she is an associate professor in Zhengzhou Institute of Aeronautical Industry Management. Her research interests include English teaching, Pragmatics and translation practice. 